\title{
Phylogenetic Groups and Pathogenicity Island Markers in Escherichia coli Isolated From Children
}

\author{
Masoumeh Navidinia ${ }^{1}$, Shahin Najar Peerayeh ${ }^{1, "}$, Fatemeh Fallah ${ }^{2}$, Bita Bakhshi ${ }^{3}$ \\ ${ }^{1}$ Department of Medical Bacteriology, Faculty of Medical Sciences, Tarbiat Modares University, Tehran, IR Iran \\ ${ }_{2}^{2}$ Pediatric Infection Research Centre, Mofid Children Hospital, Shahid Beheshti University of Medical Sciences, Tehran, IR Iran \\ ${ }^{3}$ Department of Medical Bacteriology, Faculty of Medical Sciences, Tarbiat Modares University, Tehran, IR Iran \\ ${ }^{*}$ Corresponding author: Shahin Najar Peerayeh, Department of Bacteriology, Faculty of Medical Sciences, Tarbiat Modares University, Tehran, IR Iran. Tel/Fax: +98-2182883870, E-mail: \\ najarp_s@modares.ac.ir.
}

Received: October 14, 2012; Revised: January 11, 2013; Accepted: March 9, 2013

\begin{abstract}
Background: Uropathogenic Escherichia coli (UPEC) is a causative agent in most of the urinary tract infections (UTIs) which expresses a multitude of virulence factors.

Objectives: In this study, we compared the presence of various PAI markers and phylogenetic groups in isolated E. coli from the urine of children with UTI and $E$. coli isolated from healthy children stool samples.

Materials and Methods: A total of 100 E. coli isolates were collected from September 2009 to August 2010. Biochemical and standard microbiological methods were used to identify the UPEC and fecal E. coli isolates from healthy people. All isolates subjected to phylogenetic groups typing and examination for pathogenicity islands (PAI) by multiplex PCR.

Results: We found a high number of PAI markers such as PAI ICFT073, PAI IICFT073, PAI I536, PAI IV536, PAI II J96 and PAI II536 significantly associated with UPEC. The PAI IV536 was the most detected ones among fecal E.coli isolated from healthy people while PAI I536, PAI II536 and PAI IJ96 were not seen. PCR phylogenetic groups typing revealed that uropathogenic strains were mainly found in B2 and D subgroups, while in fecal strains, A and B1 phylogenetic groups were the most common ones.

Conclusions: To our knowledge, this is the first study of the phylogenetic groups typing and PAIs marker of UPEC and fecal E. coli in Iran.
\end{abstract}

Keywords: Phylogenetic Typing Groups; Pathogenicity Island Markers; Uropathogenic Escherichia coli; Urinary Tract Infection

\section{Background}

Urinary tract infections (UTIs) are common in children around the world with chronic and recurrent infections resulting in a wide range of complications including end-stage kidney disease $(1,2)$. UTI occurs in about 3 - 5\% of girls and $1 \%$ of boys, with most girls infected before 5 years; furthermore $60-80 \%$ of girls acquire a second infection at 18 months old after the 1st UTI (3). In adults, it is estimated that $40 \%$ of women and $12 \%$ of men will experience a symptomatic UTI, with increasing incidences in their early 20 s or after age 85 , respectively. About $25 \%$ of these women will infect again within 6 to 12 months.

The primary etiologic agent associated with UTIs is the strains of uropathogenic Escherichia coli (UPEC) (4). Although UPEC is an extracellular pathogen but can invade several types of bladder cell that compose the stratified layers of the bladder urothelium. Invasion to host cell simplifies both the establishment and persistence of UPEC in the urinary tract $(5,6)$. UPEC also persist inside host urothelial cells in a more quiescent state, seques- tered within late endosomal compartments (7).

E. coli strains, present in the large intestine are categorized into 4 phylogenetic groups typing, A, B1, B2 and D; these microorganisms may be commensal, which do not harm the host or may be pathogenic, belong to groups A and B1. On the other hand, pathogenic extra intestinal $E$. coli isolates chiefly belong to phylogenetic group B2 and, to a lesser extent, group D, these isolates harbor specialized virulence factors that aid their successful colonization in the mammalian urinary tract and are responsible for intestinal and extra-intestinal disease $(2,5,8)$.

Moreover, extra-intestinal E. coli isolates have some virulence factors which are infrequent among commensal $E$. coli isolates. Some of these virulence factors are usually encoded on pathogenicity islands (PAIs) (9). Hacker et al. first described the PAI in the late 1980s. $(9,10)$. These mobile genetic elements are composed of fragments of DNA (10-200 kb) adjacent to tRNA genes and contain insertion sequences, integrases and transposases, and have a G + C content that differs from the host bacterial genome.

Implication for health policy/practice/research/medical education:

Urinary tract infections (UTIs) are common in children around the world with chronic and recurrent infections resulting in a wide range of complications including end-stage kidney disease. The primary etiologic agent associated with UTIs is the strains of uropathogenic Escherichia coli (UPEC). In this study, we compared the presence of various PAI markers and phylogenetic groups in isolated E. coli from the urine of children with UTI and E.coli isolated from healthy children stool samples

Copyright (C) 2013, Ahvaz JundishapurUniversity of Medical Sciences; Published by Kowsar Corp. This is an open-access article distributed under the terms of the Creative Commons Attribution License, which permits unrestricted use, distribution, and reproduction in any medium, provided the original work is properly cited. 


\section{Objectives}

In this study, we compared the presence of various PAI markers and phylogenetic groups in isolated E. coli from the urine of children with UTI and E. coli isolated from healthy children stool samples.

\section{Materials and Methods}

\subsection{Specimens}

This is a retrospective study from September 2009 to August 2010 on urine samples collected from 2 - 12 years old children, suspected to UTI and admitted to the nephrology ward of Mofid Children Hospital. Fresh clean catch midstream urine samples from children with UTI were collected in the sterile containers and cultured onto 5\% sheep blood agar (Merck, Germeny) and MacConkey agar (Merck, Germeny) by means of calibrated loop delivering $0.01 \mathrm{~mL}$ of the urine. Plates were incubated at $37^{\circ} \mathrm{C}$ overnight and were examined for the growth of microorganisms. All plates showing significant growth $\left(>10^{5} \mathrm{CFU} /\right.$ $\mathrm{mL}$ ) were further processed. Also, 50 E. coli isolated from stool samples from healthy children were cultured on MacConkey agar plates and incubated at $37^{\circ} \mathrm{C}$ overnight.
Strains biochemically confirmed and the E. coli were stored in Luria-Bertani (LB) broth (Sigma Aldrich, Germeny) supplemented with sterilized $15 \%$ glycerol (Sigma Aldrich, Germeny) at $-20^{\circ} \mathrm{C}$ for further examination.

\subsection{DNA Extraction}

Three to five colonies from pure and overnight cultures were suspended in $0.5 \mathrm{~mL}$ sterile distilled water and lysed by heating at $950 \mathrm{C}$ for 10 minutes and the supernatant was harvested by centrifugation at 8,000 rpm for $5 \mathrm{~min}$ utes. The supernatant was used as template DNA(11).

\subsection{Phylogenetic Groups Typing}

We used a simple and rapid PCR-based technique consisting of the combination of three DNA markers (chuA, yjaA and tspE4.C2), for phylogenetic groups typing of $E$. coli isolates (12). The expected fragment sizes were 279, 211 and 152 base pairs (bp), respectively. Multiplex-PCR procedure was performed using 3 pairs of primers in a single reaction. E. coli isolates fell into one of the four phylogenetic groups typing: A, B1, B2 or D. In this study the E. coli strain RS218 belonged to phylogenetic group B2, was used as a control in each PCR assay.

\begin{tabular}{|c|c|c|c|}
\hline Gene & Size, bp & Primer & Reference \\
\hline chuA & 279 & $\begin{array}{l}\text { F:GACGAACCAACGGTCAGGAT, } \\
\text { R:TGCCGCCAGTACCAAAGAC }\end{array}$ & 20 \\
\hline yjaA & 211 & $\begin{array}{l}\text { F:TGAAGTGTCAGGAGACGCTG, } \\
\text { R:ATGGAGAATGCGTTCCTCAA }\end{array}$ & 20 \\
\hline TSPE4.C2 & 152 & $\begin{array}{l}\text { F:GAGTAATGTCGGGGCATTCA, } \\
\text { R:CGCGCCAACAAAGTATTACG }\end{array}$ & 20 \\
\hline Multiplex PCR (A) PAI III536 & 200 & $\begin{array}{l}\text { F:CGGGCATGCATCAATTATCTTTG, } \\
\text { R:TGTGTAGATGCAGTCACTCCG }\end{array}$ & 2 \\
\hline PAI IV536 & 300 & $\begin{array}{l}\text { F:AAGGATTCGCTGTTACCGGAC, } \\
\text { R:TCGTCGGGCAGCGTTTCTTCT }\end{array}$ & 2 \\
\hline PAI IICFTO73 & 400 & $\begin{array}{l}\text { F:ATGGATGTTGTATCGCGCPS, } \\
\text { R:ACGAGCATGTGGATCTGC }\end{array}$ & 2 \\
\hline Multiplex PCR (B) PAII536 & 1800 & $\begin{array}{l}\text { F:TAATGCCGGAGATTCATTGTC, } \\
\text { R:AGGATTTGTCTCAGGGCTTT }\end{array}$ & 2 \\
\hline PAI II 536 & 1000 & $\begin{array}{l}\text { F:CCATGTCCAAAGCTCGAGC, } \\
\text { R:CTACGTCAGGCTGGCTTTG }\end{array}$ & 2 \\
\hline PAI I J96 & 400 & $\begin{array}{l}\text { F:TCGTGCTCAGGTCCGGAATTT, } \\
\text { R:TGGCATCCCACATTATCG }\end{array}$ & 2 \\
\hline PAI II J96 & 2300 & $\begin{array}{l}\text { F:GGATCCATGAAAACATGGTTAATGGG, } \\
\text { R:GATATTTTTGTTGCCATTGGTTACC }\end{array}$ & 2 \\
\hline PAI ICFTO73 & 930 & $\begin{array}{l}\text { F:GGACATCCTGTTACAGCACGCA, } \\
\text { R:TCGCCACCAATCACAGCCGAAC }\end{array}$ & 2 \\
\hline
\end{tabular}

The PCR mixtures were performed in $25 \mu \mathrm{L}$ volumes containing the following: $1 \mu \mathrm{L}$ PCR buffer $(20 \mathrm{mM}$ Tris$\mathrm{HCl}, \mathrm{pH}$ 8.0,100 mM KCl, 0.1 mM EDTA, $1 \mathrm{M}$ dithiothreitol, 0.5\% Tween 20, 0.5\% Nonidet P-40; Promega Inc., Madison, Wis.), $200 \mu \mathrm{M}$ of each deoxynucleoside triphosphates
(New England Biolabs, Beverly, MA), 2.5 mM of $\mathrm{MgCl}$, 2.0 U of Taq DNA polymerase (Promega Inc. USA), and primers as specified in Table 1 . Crude extract $(2.5 \mu \mathrm{L})$ was used as the template DNA for each PCR in Eppendorf Master Cycler gradient PCR system. PCR conditions were 
as follow: Hot start: $94^{\circ} \mathrm{C}, 4$ minutes; 30 cycle $\left(94^{\circ} \mathrm{C}\right.$ in 5 seconds, $59^{\circ} \mathrm{C}$ in 10 seconds, $72^{\circ} \mathrm{C}$ in 10 seconds) final extension: $72^{\circ} \mathrm{C}$ in 5 minutes (13).

\subsection{Detection of PAI Markers by Multiplex PCR}

All isolates were screened for the presence of PAI ICFT073, PAI IICFT073, PAI I536, PAI II536, PAI III536, PAI IV536, PAI I J96, and PAI II J96 by using two multiplex PCR. Primer sequences of PAI markers in this study are shown Table 1. PCR conditions in A and $\mathrm{B}$ reaction were as follow: Hot start: $94^{\circ} \mathrm{C} 5$ minutes; 30 cycle $\left(94^{\circ} \mathrm{C}\right.$ in 1 minute, $55^{\circ} \mathrm{C}$ in 1 minute, $72^{\circ} \mathrm{C}$ in 1 minute) final extension: $72^{\circ} \mathrm{C}$ in 10 minute. The PCR products were analyzed by gel electrophoresis on 1.5\% BIONEER agarose gels stained with ethidium bromide (Sigma Aldrich, Germeny) (0.5 mg/mL).

\subsection{Statistical Analysis}

The comparisons of proportions were tested using the McNemar test. A value of $\mathrm{P}<0.05$ was considered as significant.

\section{Results}

\subsection{Phylogenetic Groups Typing}

PCR results for three DNA markers (chuA, yjaA and tspE4. C2) were shown in Figure 1. The distribution of UPEC phylogenetic groups typing was as follow: 54 \% B2, 34 \% D, 8 \% A and $4 \% \mathrm{~B} 1$. The results showed that the distribution of B2 is more statistically significant than group D in UPEC strains $(\mathrm{P}<0.05)$. In 50 fecal E. coli isolates, the distribution of phylogenetic groups was as follow: A; $48 \%$, B1; $26 \%$, D; $22 \%$ and B2; $6 \%$.

\subsection{Pathogenicity Island Markers}

In total, $89 \%$ of UPEC isolates carried the PAIs. The distribution of various PAIs showed that the most prevalent PAI were PAI IV 536 (86\%) and PAI I CFT073 (74\%), respectively. The prevalence of other PAIs was as follow: PAI II
CFT073 (37\%), PAI II J96 (30\%), PAI I 536 (36\%) and PAI II536 (22\%). PAI III 536 and PAI I $J 96$ were detected only in $6 \%$ and $4 \%$ of UPEC, respectively. PAI IV 536 (18\%) and PAI ICFT073 (14\%) were predominant in fecal isolates. Note that some pathogenicity island markers were not seen in fecal strains. The percent of these virulence factors were more predominant in UPEC strains than fecal strains (Table 2). The PCR for detection of PAIs markers was shown in Figure 2 .

Figure 1. PCR for Phylogenetic Typing (chuA, yjaA and tspE4.C2)

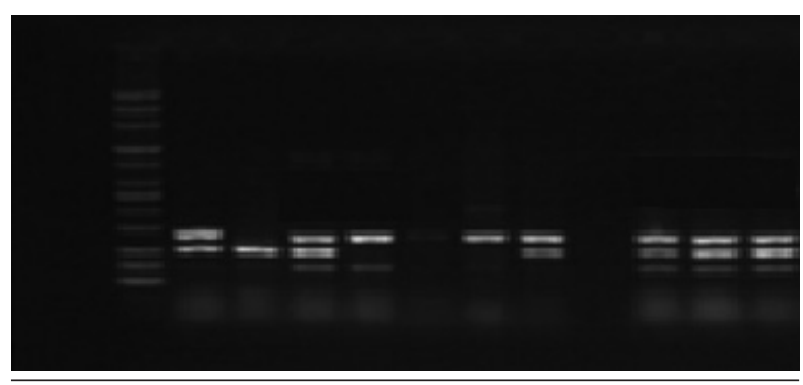

Lane 1: ladder, Lane 2,8: chuA, yjaA positive, Lane 3: TSPE4.C2 positive: Lane 4: chuA, yjaA, TSPE4. C2positive, Lane 5: chuA, TSPE4.C2 positive, Lane 6,9: negative control, Lane 7: chuA positive.

Figure 2. PCR for Detection of Pathogenicity Island Markers

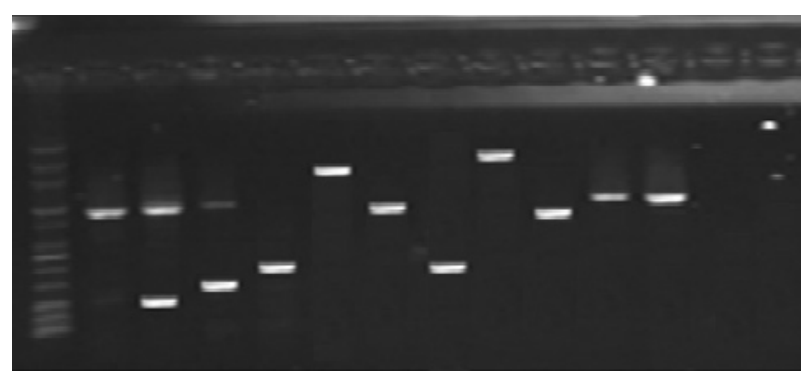

Lane 1: ladder mid range, lane 2: PAI II 536 (1000 bp), lane 3:PAI III536 (200 bp), PAI II 536 (1000 bp), lane 4: PAI IV536 (300 bp), lane 5: PAI IICFT073 (400 bp), lane 6:PAI I536 (1800 bp), lane 7:PAI II 536 (1000 bp), lane 8:PAI I J96 (400), lane 9:PAI II J96 (2300 bp), lane 10 : PAI ICFT073 (930 bp)

Table 2. The Distribution of Pathogenicity Island Marker Genes in UPEC Isolated From Patients With UTI and Fecal E. coli Isolated From Health Children Stool

\begin{tabular}{|cll}
\hline Pat hogenicity & UPEC $(\mathbf{n}=\mathbf{5 0})$, No. $(\%)$ & Fecal E. coli $(\mathbf{n}=\mathbf{5 0})$, No. $(\%)$ \\
\hline Island genes & & \\
\hline PAI III536 & $3(6)$ & $1(2)$ \\
\hline PAI IV536 & $43(86)$ & $9(18)$ \\
\hline PAI IICFT073 & $19(37)$ & $3(6)$ \\
\hline PAI I536 & $18(36)$ & 0 \\
\hline PAI II 536 & $11(22)$ & 0 \\
\hline PAI I J96 & $2(4)$ & 0 \\
\hline PAI II J96 & $15(30)$ & $2(4)$ \\
\hline PAI ICFT073 & $37(74)$ & $7(14)$ \\
\hline Total & $148(37)$ & $22(5.5)$ \\
\hline
\end{tabular}

Jundishapur J Microbiol. 2013;6(10):e8362 


\subsection{Distribution of PAIs According to Phylogenetic Groups in E. coli Isolates}

The phylogenetic group B2 containing PAI IV536 was the predominant group among UPEC (Table 3). The total number of PAIs in urinary isolates belonging to phylo- genetic groups B2 (27.75\%) and D (15\%) were significant. In contrast, the number of PAI in fecal isolates collected from phylogenetic group A (1.5\%) and D (3\%) was the highest. (Table 3) Noteworthy, there was a positive association between phylogenetic group B2 and the presence of PAIs for UPEC $(\mathrm{P}<0.001)$.

\begin{tabular}{|c|c|c|c|c|}
\hline PAI Markers & $\mathbf{A}$ & B1 & B2 & D \\
\hline \multicolumn{5}{|l|}{ PAI III536 } \\
\hline UPEC & 0 & 0 & 2 & 0 \\
\hline Fecal & 0 & 0 & 1 & 0 \\
\hline \multicolumn{5}{|l|}{ PAI IV536 } \\
\hline UPEC & 0 & 0 & 26 & 32 \\
\hline Fecal & 2 & 1 & 0 & 6 \\
\hline \multicolumn{5}{|l|}{ PAI IICFT073 } \\
\hline UPEC & 0 & 0 & 18 & 0 \\
\hline \multicolumn{5}{|l|}{ Fecal } \\
\hline & 1 & 0 & 1 & 1 \\
\hline \multicolumn{5}{|l|}{ PAI I536 } \\
\hline UPEC & 0 & 0 & 17 & 2 \\
\hline Fecal & 0 & 0 & 0 & 1 \\
\hline \multicolumn{5}{|l|}{ PAI II536 } \\
\hline UPEC & 0 & 0 & 12 & 0 \\
\hline Fecal & 0 & 0 & 0 & 0 \\
\hline \multicolumn{5}{|l|}{ PAI I J96 } \\
\hline UPEC & 0 & 0 & 2 & 0 \\
\hline Fecal & 0 & 0 & 0 & 0 \\
\hline \multicolumn{5}{|l|}{ PAI II J96 } \\
\hline UPEC & 0 & 0 & 12 & 0 \\
\hline Fecal & 1 & 0 & 1 & 0 \\
\hline \multicolumn{5}{|l|}{ PAI ICFTO73 } \\
\hline UPEC & 0 & 1 & 22 & 26 \\
\hline Fecal & 2 & 1 & 0 & 4 \\
\hline
\end{tabular}

\section{Discussion}

About 70 to $95 \%$ of community-acquired and 50\% of all hospital acquired infections is caused by E. coli. The molecular biology details of extra intestinal E. coli are poorly understood. Uropathogenic E. coli (UPEC) can grow extra intestinally and this enables them to cause a variety of diseases. It is now demonstrated that there are a subset of fecal E. coli containing some virulence factors which can colonize in periurethral area, enter to the urinary tract and cause symptomatic disease such as UTI. The mentioned pathotypes are named "UPEC" (14). We studied phylogenetic and pathotypic comparison of concurrent urine and fecal E. coli isolates from children in 2010. We analyzed the urine samples and found that the prevalence of phylogenetic group B2 was dominant (5). In our study, E. coli isolates from urine samples dra- matically differed from fecal E. coli isolates with regards to some virulence factors such as specific pathogenicity island markers and phylogenetic group B2 and D (15-17). Similar observation has been made by Clermont et al. in 2000 (18). According to the Herzer et al. (19) reports and our study, the pathogenicity islands were enriched in $E$. coli isolates from urinary tract infections that mostly belong to phylogenetic group B2 and D.

Dobrindt et al. (20) in 2002 studied the genetic structure and distribution of four pathogenicity islands (PAI I536 to PAI IV536) in UPECstrain 536. They also suggested that PAIs were detectable in pathogenic E. coli isolates than fecal ones. Our results showed that the mean number of PAIs per isolate was high in UPEC; however, E. coli isolates belong to groups A and B1 appeared to have fewer 
pathogenicity island markers than the pathogenic isolates.

We noted that phylogenetic group B2 was uncommon in fecal isolates. This phylogenetic group is highly virulent and when colonize in intestine, may cause of UTI (2). We can conclude that genomic differences between UPEC and fecal E. coli strains were mainly restricted to phylogenetic groups and large pathogenicity islands.

\section{Acknowledgements}

We thank Prof. A. Karimi and Dr. S. Maham, Dr. M. Mohkam and N. Heidari for their support.

\section{Authors' Contribution}

None declared.

\section{Financial Disclosure}

No Conflict of interest was considered in this article.

\section{Funding/Support}

This work was supported by Faculty of Medical Sciences of Tarbiat Modares University and Pediatric Infection Research Center of Mofid Children's Hospital in Tehran.

\section{References}

1. Blango MG, Mulvey MA. Persistence of uropathogenic Escherichia coli in the face of multiple antibiotics. Antimicrob Agents Chemother. 2010;54(5):1855-63.

2. Sabate M, Moreno E, Perez T, Andreu A, Prats G. Pathogenicity island markers in commensal and uropathogenic Escherichia coli isolates. Clin Microbiol Infect. 2006;12(9):880-6.

3. Kliegman Robert. Nelson textbook of pediatrics.: Saunders Elsevier Philadelphia; 2007.

4. Sivick Kelsey E, Mobley Harry LT. Waging war against uropathogenic Escherichia coli: winning back the urinary tract. Infect Immun. 2010;78(2):568-585.

5. Johnson JR, Scheutz F, Ulleryd P, Kuskowski MA, O'Bryan TT, Sandberg T. Phylogenetic and pathotypic comparison of concurrent urine and rectal Escherichia coli isolates from men with febrile urinary tract infection. J Clin Microbiol. 2005;43(8):3895-900.

6. Mulvey Matthew A, Schilling Joel D, Martinez Juan J, Hultgren
Scott J. Bad bugs and beleaguered bladders: Interplay between uropathogenic Escherichia coli and innate host defenses. Proceedings of the National Academy of Sciences. 2000;97(16):88298835 .

7. Foxman B. Recurring urinary tract infection: incidence and risk factors. Am J Public Health. 1990;80(3):331-3.

8. Katouli Mohammad. Population structure of gut Escherichia coli and its role in development of extra-intestinal infections. Iran J Microbiol. 2010;2(2):59.

9. Hacker J, Kaper JB. Pathogenicity islands and the evolution of microbes. Annu Rev Microbiol. 2000;54:641-679.

10. Karch H, Schubert S, Zhang D, Zhang W, Schmidt H, Ölschläger $\mathrm{T}$, et al. A genomic island, termed high-pathogenicity island, is present in certain non-O157 Shiga toxin-producing Escherichia coli clonal lineages. Infect Immun. 1999;67(11):5994-6001.

11. Sabarinath Arathy, Deallie Claude, Belot Guillaume, Vanpee Guillaume, Matthew Vanesa, Sharma Ravindranath, et al. Antimicrobial Resistance and Phylogenetic Groups of Commensal Escherichia Coli Isolates from Healthy Pigs in Grenada. 2011. Available from: www.webmedcentral.com.

12. Hasan AS, Nair D, Kaur J, Baweja G, Deb M, Aggarwal P. Resistance patterns of urinary isolates in a tertiary Indian hospital. J Ayub Med Coll Abbottabad. 2007;19(1):39-41.

13. Dhakal BK, Kulesus RR, Mulvey MA. Mechanisms and consequences of bladder cell invasion by uropathogenic Escherichia coli. Eur J Clin Invest. 2008;38 Suppl 2:2-11.

14. Abdallah KS, Cao Y, Wei DJ. Epidemiologic Investigation of Extraintestinal pathogenic E. coli (ExPEC) based on PCR phylogenetic group and fimH single nucleotide polymorphisms (SNPs) in China. Int J Mol Epidemiol Genet. 2011;2(4):339-53.

15. Li B, Sun JY, Han LZ, Huang XH, Fu Q, Ni YX. Phylogenetic groups and pathogenicity island markers in fecal Escherichia coli isolates from asymptomatic humans in China. Appl Environ Microbiol. 2010;76(19):6698-700.

16. Manges AR, Dietrich PS, Riley LW. Multidrug-resistant Escherichia coli clonal groups causing community-acquired pyelonephritis. Clin Infect Dis. 2004;38(3):329-34.

17. Terai A, Ishitoya S, Mitsumori K, Ogawa O. Molecular epidemiological evidence for ascending urethral infection in acute bacterial prostatitis. JUrol. 2000;164(6):1945-7.

18. Clermont O, Bonacorsi S, Bingen E. Rapid and simple determination of the Escherichia coli phylogenetic group. Appl Environ Microbiol. 2000;66(10):4555-8.

19. Herzer PJ, Inouye S, Inouye M, Whittam TS. Phylogenetic distribution of branched RNA-linked multicopy single-stranded DNA among natural isolates of Escherichia coli. J Bacteriol. 1990;172(11):6175-81.

20. Dobrindt U, Blum-Oehler G, Nagy G, Schneider G, Johann A, Gottschalk G, et al. Genetic structure and distribution of four pathogenicity islands (PAI I(536) to PAI IV(536)) of uropathogenic Escherichia coli strain 536. Infect Immun. 2002;70(11):6365-72. 